El grito de arrogancia no se oye más: quedan sólo los acentos de la miseria y el abandono. Y el poeta que ha visto cómo el abismo "devora" al torrente, sabe que "en pocos años / ya devorado habrá la tumba fría" a él mismo, el cantor del Niágara. En cuanto a Espronceda, se di. rige melancólicamente al sol con estas palabras:

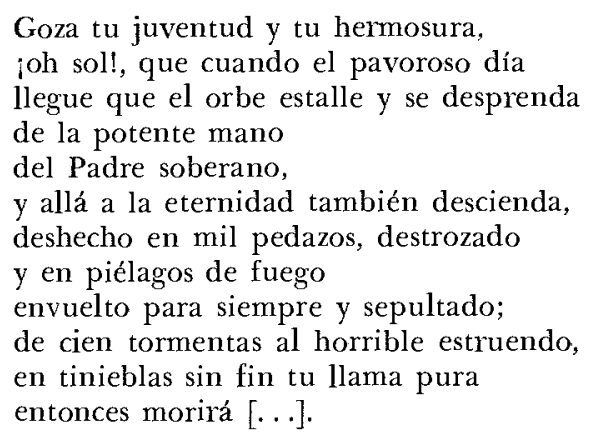

Es la misma falta de esperanza, la misma romántica zozobra en los dos poetas. Con una diferencia: Heredia abandona el plano metafórico y se refiere a sí mismo, a su propia "juventud" agostada, mientras que Espronceda se refiere a la "juventud" del sol, a su hermosura condenada a morir; pero es claro, en vista de su identificación previa con el astro, que lo que nos declara en esos versos es su propia angustiada desesperanza.

Howard Slingerland

Tufts University.

\title{
TRES NAHUATLISMOS EN ORIENTE
}

En su interesante artículo "Influencia hispanomexicana en el idioma tagalo", $H M x, 14$ (1964-65), 261-271, José Villa Panganiban menciona tres nahuatlismos del tagalo que merecen un examen más detallado.

I. Según ese artículo, el fitónimo mexicano jicama (Pachyrrhizus erosus) ${ }^{1}$ se manifiesta bajo dos formas en las Filipinas: a) singhamas (sust. sing.) y b) hikama. La segunda forma puede considerarse como un préstamo relativamente tardio que el tagalo tomó del español postcolonial. La que nos interesa aquí es la primera: en vista de su estruc-

nífica escena... Yo no sé qué analogia tiene aquel espectáculo solitario y agreste con mis sentimientos... Allí escribí apresuradamente los versos que te incluyo y que sólo expresan débilmente una parte de mis sensaciones. ¡Cuántas cavilaciones sublimes y profundas puede excitar aquella situación en una alma serena y tranquila!" (apud M. García Garófalo, Vida de José Maria Heredia en México, México, 1945, pp. 179-184).

1 La designación Pachyrrhizus erosus se prefiere a la de Pachyrrhizus jicamas. Véase J. I. Briquer, International rules of botanical nomenclature (1935), p. 100. 
tura fonética, singhamas parece haberse introducido en las Filipinas antes de mediados del siglo xvn. La $s$ - inicial procede evidentemente, no de la $j$ - actual $(=[\mathrm{x}])$, sino de la antigua $x-(=[\check{\mathrm{s}}])$ de la palabra xicama < náhuatl xicamat $l^{2}$. En cuanto a la nasal $-n$-, debe de ser el resultado de una asimilación anticipatoria a la $-m$ - de xicama. La -s final reproduce el morfema español de plural, a causa de la frecuencia con que se usa el plural cuando se habla del cultivo de plantas alimenticias ${ }^{3}$. Después de la introducción de la jícama mexicana en las Filipinas, testimoniada por el tag. singhamas, la planta fue llevada durante la época de Rumpf (1653-1692) a la Península malaya, donde se estableció su cultivo (I. H. Burkill, $A$ dictionary of the economic products of the Malay Peninsula, London, 1935, t. 2, p. 1619). Varias plantas cultivadas se han exportado de Luzón al este de las Filipinas, como puede comprobarse por las designaciones javanesas del chicozapote (sáwo manila), del cacahuate (kátjang manila) y del guanábano (lángka manila), todas las cuales incluyen el topónimo Manila (cf. E. D. MerriLl, Plant life of the Pacific world, New York, 1945, p. 229). Entre los nombres malayos de la jícama se encuentra la voz sengkuwang (BurkiLL, loc. cit.), que bien puede ser una adaptación local del tag. singhamas.

II. El étimon chancana (sic) que ofrece Villa Panganiban para el tag. sangkaka debe cambiarse por chancaca. Además, no se trata del adjetivo que significa 'negruzco', sino del sustantivo mexicano chancaca 'azúcar prieta o panocha, en cuerpos hemisféricos', así definido por F. J. Santamaria en su Diccionario general de americanismos (s.v. chancaca, 3). El mismo autor afirma en su Diccionario de mejicanismos que, aunque esta voz no se conoce en la capital ni en los estados vecinos, se sospecha su existencia en el oeste, puesto que la documenta el lexicógrafo jalisciense Mendoza. Opina también que la palabra es de origen náhuatl y que pasó de México al Perú y a Chile, donde se emplea con un sentido semejante. Según F. Ramos y Duarte (Diccionario de mejicanismos, México, 1898), chancaca viene del náhuatl chian 'tierra' + caca < cacátzac 'cosa negra'. Ya en ${ }^{1571}$ fray Alonso de Molina había documentado en su Vocabulario en lengua castellana y mexicana la palabra chiancaca como 'maçapán de la tierra'. El hecho de que la caña de azúcar haya sido importada del Viejo Mundo no debiera impedirnos aceptar la procedencia náhuatl de la palabra. La existencia en Honduras de chancaca con la acepción de 'torta de harina de trigo o de maíz con miel' (A. Membreño, Hondureñismos, México, 1912) podría indicar que su sentido original de 'masa o pasta de harina de maíz y miel' cambió al de 'último azúcar moreno que queda en las calderas' cuando se inició la fabricación de azúcar en México. En efecto, la consistencia

2 Según Penro Henríqufz Ureña, BDH, t. 4, pp. xv-xvi, el sonido [Š] del náhuatl se conservó en el español de México durante el siglo xvl y parte del xvn.

3 El mismo fenómeno se observa en tag. sibúyas < cebolla (cit. por Elmer D. Merrill, $A$ dictionary of the plant names of the Philippine Islands, Manila, 19og). Se pueden comparar las formas byabas, gyabas < guayaba, citadas por Villa Panganiban. También el guameño conoce hikamas y seboyas con $-s$ (W. E. SAFFord, The useful plants of the Island of Guam, Washington, 1905, pp. 204-205). 
granulosa de una mezcla de maicena y miel no se distingue mucho de la que tiene el azúcar prietó.

III. La pretendida voz mexicana avocado que aduce Villa Panganiban como étimon del tag. abukado 'árbol parecido al aguacate' plantea varios problemas. La única designación mexicana que da Santamaría para la Persea Americana es aguacate (la fruta), aguacatero (el árbol). En vano buscamos en el español mexicano una documentación de la forma avocado. Sin embargo, Santamaría (Dicc. general) registra abacado como 'nombre que se da al aguacate en las Antillas', y la misma forma aparece en la Enciclopedia del idioma de Martín Alonso. Nos parece que ésta sería la forma que dio origen a la antigua voz portuguesa abacado 'aguacatero', reemplazada hoy por abacateira y abacateiro (António de Morais Silva, Grande dicionário da lingua portuguesa, Lisboa, 1949-1959). El nombre corriente portugués de la fruta, abacate, ostenta, en la terminación -ate, su parentesco con el mex. aguacate < náh. ahuacatl. En cuanto a la forma abacado, no se puede descontar la posibilidad de que tenga sus raíces en los nombres ingleses de la planta. Una documentación amplia de estas designaciones se ve en el Oxford English dictionary (J. A. H. MurRay et al.): 1697 avogato peartree, 1763 avocato, $18_{30}$ avocado pear, 1864 avigato. La pronunciación de la vocal intertónica en inglés pudo haber sido interpretada por los españoles como la representación inglesa del sonido $a$. De esa manera ingl. avocado se convirtió en esp. abacado. Pero ¿̨cuál es el origen de las formas inglesas? Por supuesto los ingleses tomaron del español el nombre de la planta. No es imposible que haya existido en la Nueva España, al lado de aguacate, una forma *abocado (no documentada) que floreció brevemente antes de desaparecer. Esta variante podría ser el resultado de una etimología popular basada en la influencia del sust. bocado (siglos xvI-XviII) 'comida, especialmente la apetitosa' o del verbo abocadar (siglo xvn) 'coger buen bocado' (apud Martín Alonso, loe. cit.). El tag. abukado puede ser el continuador de nuestra hipotética forma mexicana.

University of Pennsylvania.

M. ROY HARRIS

4 La costumbre (mencionada por Villa Panganiban) de moldear el azúcar "en medias cáscaras de cacao" podría atestiguar el mismo uso en el México colonial. Aquí viene a cuento lo que dice Juan de Arona en su Diccionario de peruanismos: "La azúcar de la gente pobre [...]. Es un bollo prieto de figura hemisférica y como del tamaño de un pequeño plato sopero [...]. Se labran en unas tablas largas con escavaciones circulares y someras abiertas paralelamente de dos en dos en toda la superficie, y que constituyen el molde. Después de mojarlas con agua para que el melado no se pegue, se va vertiendo éste en las dichas escavaciones. Tal es la forma más general de la chancaca". 